\title{
Enhanced expression of early mitotic inhibitor-1 predicts a poor prognosis in esophageal squamous cell carcinoma patients
}

\author{
CHENGQI GUAN $^{1 *}$, JIANFENG ZHANG $^{1 *}$, JIANGUO ZHANG $^{2}$, HUI SHI $^{3}$ and RUNZHOU NI ${ }^{1}$ \\ Departments of ${ }^{1}$ Gastroenterology, ${ }^{2}$ Pathology and ${ }^{3}$ Thoracic Surgery, \\ Affiliated Hospital of Nantong University, Nantong, Jiangsu 226001, P.R. China
}

Received March 12, 2015; Accepted April 8, 2016

DOI: $10.3892 / \mathrm{ol} .2016 .4611$

\begin{abstract}
Early mitotic inhibitor-1 (Emi1), as a key cell cycle regulatory gene, induces $\mathrm{S}$ phase and mitotic entry by controlling anaphase-promoting complex substrates. Emil overexpression may be a prognostic factor for patients with invasive breast cancer. However, its expression and clinical significance in esophageal squamous cell carcinoma (ESCC) remain unknown. In the present study, Emi1 was overexpressed in ESCC samples, contrarily to their neighboring normal tissues. The expression of Emi1 was correlated with histological differentiation $(\mathrm{P}=0.032)$, lymphatic metastasis $(\mathrm{P}=0.006)$ and $\mathrm{Ki}-67$ expression $(\mathrm{P}=0.028)$. Multivariate analysis indicated that the presence of lymphatic metastasis and the protein expression levels of Emil and Ki-67 were all independent prognostic factors for ESCC patients $(\mathrm{P}=0.042,0.018$ and 0.001 , respectively). In vitro, however, the expression of Emil was upregulated in the ECA109 cell line following release from serum starvation. In addition, depletion of endogenous Emil by small interfering RNA could effectively reduce cell proliferation. Thus, the present data indicated that Emil expression was upregulated in ESCC tissues and correlated with poor survival in ESCC patients, and suggested that Emi1 may be an independent prognostic factor for ESCC patients.
\end{abstract}

\section{Introduction}

Esophageal cancer(EC), the eighth most common type of cancer in the world, may be pathologically divided into two major categories: Esophageal adenocarcinoma and esophageal squamous cell carcinoma (ESCC) $(1,2)$. In China, EC is highly prevalent, and is the fourth-ranked cancer in terms of incidence (3).

Correspondence to: Professor Runzhou Ni, Department of Gastroenterology, Affiliated Hospital of Nantong University, 20 Xisi Road, Nantong, Jiangsu 226001, P.R. China

E-mail: nirz@163.com

${ }^{*}$ Contributed equally

Key words: esophageal squamous cell carcinoma, early mitotic inhibitor-1, prognosis
Due to the difficulties in early diagnosis and poor treatment efficacy, the 5-year survival rate of ESCC is considerably low, ranging from $15-25 \%$ (1-4). Thus far, numerous studies have been conducted to attempt to clarify the fundamental molecular mechanisms and biological behavior of ESCC.

Abnormalities in the cell cycle are essential in the process of human carcinogenesis, resulting in an increase in cell proliferation and/or a reduction in the death of abnormal cells (5). Several key proteins are required to maintain the integrity of the normal cell cycle, and aberrant expression of proteins such as cyclins A and B1 leads to an abnormal cell cycle (5-8). Cyclin A, as an important checkpoint mechanism in the G1-S transition of the cell cycle, is expressed just prior to the start of DNA synthesis, while cyclin B1 acts as a mitotic cyclin protein in the G2-M transition (9). It has been verified that the expression of cyclin A and cyclin B1 is remarkably upregulated in human ESCC, as opposed to neighboring normal tissues $(10,11)$. Therefore, cyclins A and B1 may be implicated in the tumorigenesis and evolution of malignancies (9-13). Early mitotic inhibitor-1 (Emi1), as a cell cycle regulator, governs the progression to $\mathrm{S}$ phase and mitosis by stabilizing key ubiquitination substrates of anaphase-promoting complex, including cyclins A and B1 (14-16). It has been previously reported that excess Emil added to Xenopus egg extracts prevents cyclins A and B1 degradation, and is required for accumulation of cyclins A and B1 (17). In addition, upregulation of Emil messenger RNA exists in numerous malignant tumors, and its overexpression produces mitotic defects, possibly resulting in tumorigenesis (18-20).

Despite the frequent dysfunction of the cell cycle machinery in human ESCC, the expression and clinical significance of Emil protein in ESCC remain unclear. In the present study, Emil protein expression was determined by immunohistochemistry and immunoblotting in ESCC, and the associations between Emil and clinicopathological variables and prognosis were investigated. In addition, ECA109 cells were transfected with Emil small interfering (si)RNA vectors in vitro to investigate the functionality of Emil as a potential therapeutic target for ESCC.

\section{Materials and methods}

Patients and tissue specimens. In the present study, 90 ESCC (55 males and 35 females) aged 31-80 years (mean, 60 years) were retrieved from the archival files of the Department of 
Pathology of the Affiliated Hospital of Nantong University (Nantong, China) from January 2000 to December 2004. None of the patients were treated with radiation, chemotherapy or immunotherapy prior to operation. Upon signing informed consent, patients were questioned regarding their demographic characteristics. Histological differentiation was divided into three grades, namely, grade I (well differentiated), II (moderately differentiated) and III (poorly differentiated). The 90 patients examined were grouped into the above three grades (20 patients into grade I, 50 into grade II and 20 into grade III). In addition, invasion of lymphatic and blood vessels was evaluated microscopically.

Tissue specimens were treated as soon as surgical removal was completed. For histological examination, all tumorous and para-cancerous tissue portions were processed into $10 \%$ buffered formalin-fixed, paraffin-embedded blocks. Protein expression was analyzed in 8 tumorous and para-cancerous tissue samples stored at $-80^{\circ} \mathrm{C}$.

Immunohistochemical analyses. The tissue sections were deparaffinized through a graded ethanol series, and endogenous peroxidase activity was blocked by immersion in $0.3 \%$ hydrogen peroxide $\left(\mathrm{H}_{2} \mathrm{O}_{2}\right)$. Next, the sections were treated in $10 \mathrm{mmol} / \mathrm{l}$ citrate buffer ( $\mathrm{pH}$ 6.0; Beijing Zhongshan Jinqiao Biotechnology Co., Ltd., Beijing, China), and heated to $121^{\circ} \mathrm{C}$ in a pressure cooker for $20 \mathrm{~min}$ for antigen retrieval. Upon washing in phosphate-buffered saline (PBS) (pH 7.2), 10\% goat serum (Beijing Zhongshan Jinqiao Biotechnology Co., Ltd.) was applied for $1 \mathrm{~h}$ at room temperature to block nonspecific reactions. Then, the sections were incubated for $12 \mathrm{~h}$ at $4^{\circ} \mathrm{C}$ with anti-Emil rabbit polyclonal antibody (1:100; cat. no. sc-30182; Santa Cruz Biotechnology, Inc., Dallas, TX, USA), and anti-Ki-67 mouse monoclonal antibody (1:100; clone 7B11; Zymed; cat. no. MA5-15690; Thermo Fisher Scientific, Inc., Waltham, MA, USA). Negative control sections were also processed in parallel with a nonspecific immunoglobulin (Ig)G (cat. no. I5006-10MG; Sigma-Aldrich, St. Louis, MO, USA) applied at the same concentration as the above primary antibodies. All sections were treated using the peroxidase-antiperoxidase method (Dako, Glostrup, Denmark). Upon washing in PBS, the peroxidase reaction was visualized by incubating the slides with 3,3'-diaminobenzidine tetrahydrochloride in $0.05 \mathrm{~mol} / \mathrm{l}$ Tris buffer $(\mathrm{pH} 7.6)$ including $0.03 \% \mathrm{H}_{2} \mathrm{O}_{2}$. Upon washing in water, the slides were counterstained with hematoxylin, dehydrated in a graded alcohol series and coverslipped.

Immunohistochemical evaluation. All the immunostained sections were assessed in a blinded approach without knowing the patients' clinical and pathological variables. Regarding Emil assessment, staining intensity was evaluated using a four rating-level-scheme, where scores ranging from 0 to 3 indicated negative, weak, medium and strong staining, respectively. For extent of staining, a five rating-level-scheme was employed. Thus, based on the total amount of positive stained areas in the whole carcinoma region, the extent of staining was evaluated with scores ranging from 0 to 4 as follows: $0,0 \%$; $1,1-25 \% ; 2,26-50 \% ; 3,51-75 \%$; and $4,76-100 \%$. The sum of intensity and extent scores was used as the final staining score (0-7) for Emi1. Tumors were considered to be positive when their final staining scores were $\geq 3$ (21). In each specimen, five high-power fields were randomly selected for Ki-67 assessment, together with examination of nuclear staining. To determine the medium percentage of immunostained cells among the total number of cells, $>500$ cells were counted. To avoid possible technical errors, staining was performed twice, and similar results were achieved. All the aforementioned evaluations were conducted independently by two investigators with identical results.

Cell culture and cell cycle analysis. The human ESCC cell line ECA109 was purchased from the Chinese Academy of Sciences (Beijing, China) and cultured in RPMI-1640 medium (Gibco; Thermo Fisher Scientific, Inc.) with $10 \%$ heat-inactivated fetal calf serum (Gibco; Thermo Fisher Scientific, Inc.), $2 \mathrm{mM}$ L-glutamine and $100 \mathrm{U} / \mathrm{ml}$ penicillin-streptomycin mixture (Gibco; Thermo Fisher Scientific, Inc.) at $37^{\circ} \mathrm{C}$ and $5 \% \mathrm{CO}_{2}$. Cells were fixed in $70 \%$ ethanol for $1 \mathrm{~h}$ at $4^{\circ} \mathrm{C}$, and then incubated with $1 \mathrm{mg} / \mathrm{ml}$ RNase A for $30 \mathrm{~min}$ at $37^{\circ} \mathrm{C}$ for cell cycle analysis. Next, cells were stained with propidium iodide (50 mg/ml; BD Biosciences, San Jose, CA, USA) and analyzed using a flow cytometer (FACScan; BD Biosciences) and CellQuest Pro Acquisition and Analysis software (BD Biosciences).

siRNA and transfection. The pSilencer 4.1-CMV Emi1-siRNA expression vectors were constructed by incorporating the siRNA targeting nucleotide residues AAGCAC TAGAGACCAGTAGAC (Emi1-si1) and ACTTGCTGC CAGTTCTCA (Emi1-si2) in the pSilencer 4.1-CMV vector (Thermo Fisher Scientific, Inc.). ECA109 cells were seeded the day preceding transfection using RPMI-1640 medium with $10 \%$ fetal calf serum but without antibiotics. Transient transfection of Emi1-siRNA and control siRNA vectors was conducted using Lipofectamine ${ }^{\circledR}$ LTX \& PLUS ${ }^{\text {TM }}$ reagent (Thermo Fisher Scientific, Inc.) in Opti-MEM ${ }^{\circledR}$ (Thermo Fisher Scientific, Inc.), as suggested by the manufacturer. Cells were incubated with the pSilencer vectors and Lipofectamine ${ }^{\circledR}$ LTX \& PLUS ${ }^{\text {TM }}$ reagent complexes for $4 \mathrm{~h}$ at $37^{\circ} \mathrm{C}$, and harvested $48 \mathrm{~h}$ post-transfection. The experiments were repeated three times.

Cell Counting Kit (CCK)-8 assay. Cell proliferation was detected by the commercial CCK- 8 method (Dojindo Molecular Technologies, Inc., Kumamoto, Japan), according to the manufacturer's protocol. Shortly, cells were seeded into 96-well cell culture cluster plates at a concentration of $2 \times 10^{4}$ cells/well in volumes of $100 \mu 1$, and cultured overnight. CCK-8 reagent was added to a subset of wells containing cells under different treatments, and incubated for $2 \mathrm{~h}$ at $37^{\circ} \mathrm{C}$. The absorbance was next quantified at $450 \mathrm{~nm}$ with an automated plate reader.

Western blot analysis. Tissues and cells were rapidly homogenized in a homogenization buffer containing $1 \%$ Triton $\mathrm{X}-100,1 \mathrm{M}$ Tris- $\mathrm{HCl}$ ( $\mathrm{pH} 7.5), 10 \%$ sodium dodecyl sulfate (SDS), $1 \%$ Nonidet $^{\text {TM }} \mathrm{P}-40,10 \mu \mathrm{g} / \mathrm{ml}$ leupeptin, $0.5 \%$ sodium deoxycholate, $10 \mu \mathrm{g} / \mathrm{ml}$ aprotinin, $0.5 \mathrm{M}$ ethylenediaminetetraacetic acid and $1 \mathrm{mM}$ phenylmethylsulfonyl fluoride, prior to be centrifuged at $10,000 \mathrm{~g}$ for $30 \mathrm{~min}$ to collect 

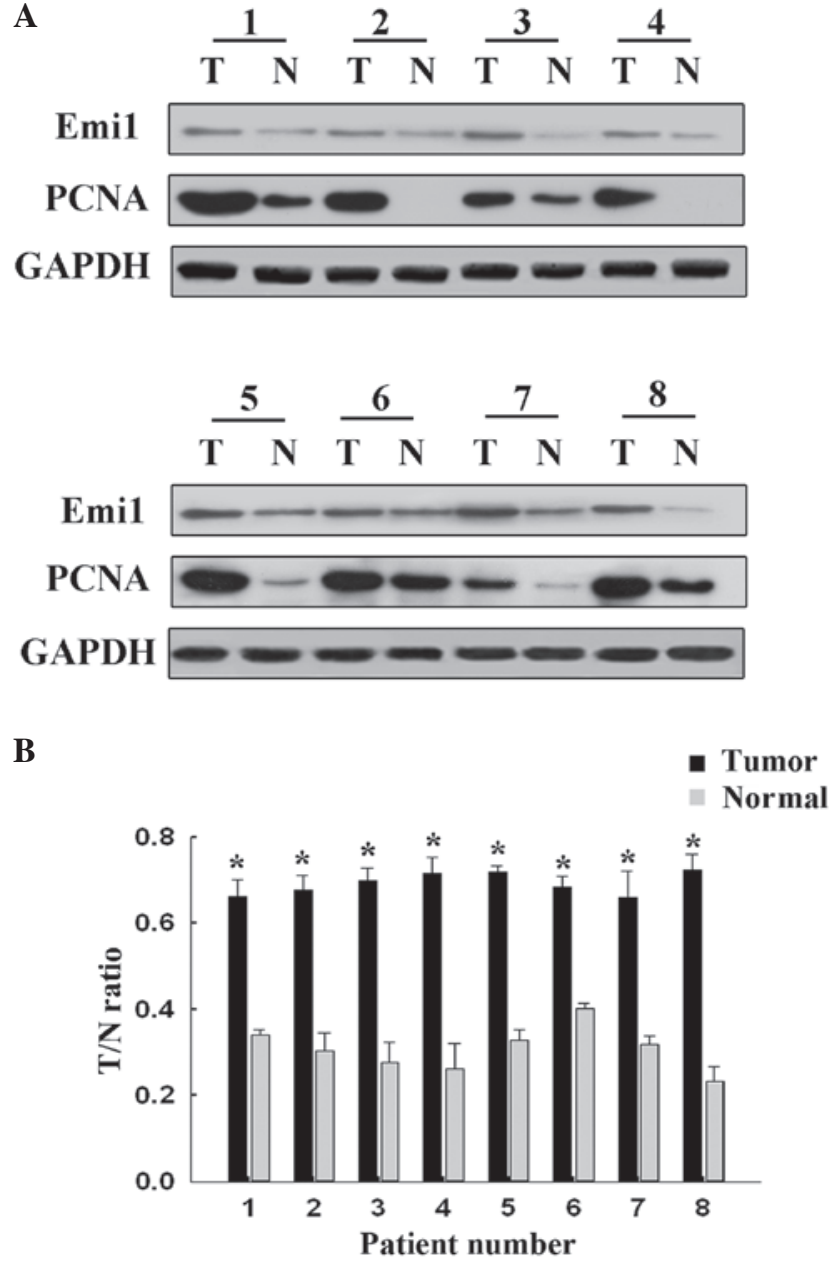

Figure 1. Emi1 is overexpressed in ESCC, compared with para-cancerous tissues. (A) Western blotting of 8 representative paired samples of ESCC tissues and para-cancerous tissues immunoblotted against Emil. Whole-cell lysates were prepared from tissue specimens obtained from ESCC and para-cancerous tissues. In 6 of the 8 samples tested, Emil expression levels were significantly higher in ESCC than in paired para-cancerous tissues. Proliferating cell nuclear antigen was used as a tumor proliferative marker, while GAPDH was used as a control for protein loading and integrity. (B) Quantification of the results shown in panel A. "P $<0.05$. ESCC, esophageal squamous cell carcinoma; Emil, early mitotic inhibitor-1; PCNA, proliferating cell nuclear antigen; GAPDH, glyceraldehyde 3-phosphate dehydrogenase $\mathrm{T}$, tumor; $\mathrm{N}$, normal.

the supernatant. Protein concentrations were measured with a Bio-Rad protein assay (Bio-Rad Laboratories, Inc., Hercules, CA, USA). 2X SDS loading buffer was used to dilute the supernatant, which was next boiled. Proteins were separated by SDS-polyacrylamide gel electrophoresis, and then transferred to polyvinylidene difluoride membranes (EMD Millipore, Billerica, MA, USA). The membranes were blocked with $5 \%$ dried skimmed milk in Tris-buffered saline and Tween 20, containing $20 \mathrm{mM}$ Tris, $0.05 \%$ Tween 20 , and $150 \mathrm{mM} \mathrm{NaCl}$. Following $2 \mathrm{~h}$-incubation at room temperature, the membranes were incubated overnight with the following antibodies: Anti-Emil (1:500; cat. no. sc-30182), anti-cyclin A (1:500; cat. no. sc-751), anti-cyclin B1 (1:500; cat. no. sc-25764), anti-proliferating cell nuclear antigen (1:1,000; cat. no. sc-56) and anti-glyceraldehyde 3-phosphate dehydrogenase $(1: 1,000$; cat. no. sc-25778). All the above primary antibodies were purchased from Santa
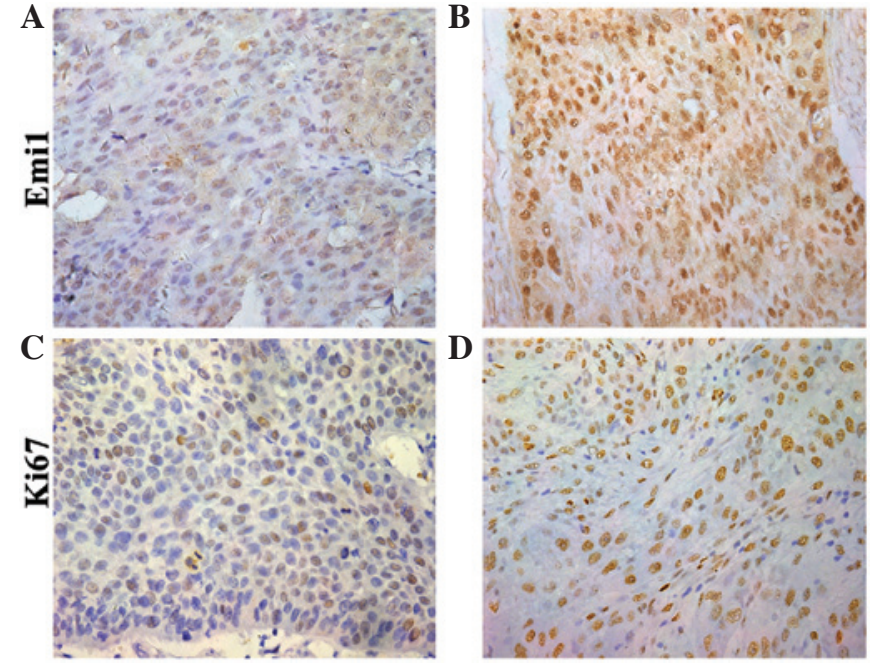

Figure 2. Immunohistochemical staining of Emi1 and Ki-67 in ESCC tissues Paraffin-embedded tissue sections were stained with antibodies against Emi1 and Ki-67, and counterstained with hematoxylin.(A and B) Emil reactivity (magnification, x400). (C and D) Ki-67 staining (SP x400). (A and C) Well differentiated ESCC specimens displayed (A) weak Emil and (C) weak Ki-67 immunostaining. (B and D) Moderate/poor differentiated ESCC tissues exhibited (B) strong Emil (B) and (D) strong brown nuclear Ki-67 immunostaining. ESCC, esophageal squamous cell carcinoma; Emi1, early mitotic inhibitor-1.

Cruz Biotechnology, Inc. Horseradish peroxidase-linked IgG (cat. no. sc-2030; Santa Cruz Biotechnology, Inc.) was used as a secondary antibody. The immunoreactive bands were visualized by chemiluminescence (NEN Life Science Products, Inc., Boston, MA, USA), and exposed to X-ray films, which were then scanned using a Molecular Dynamics densitometer (GE Healthcare Life Sciences, Chalfont, UK) and the Odyssey infrared imaging system (LI-COR Biotechnology, Lincoln, NE, USA). The experiments were repeated on three separate occasions.

Statistical analysis. The statistical software Stata version 11.0 (StataCorp LP, College Station, TX, USA) was used for statistical analysis. The association between Emil protein expression and clinicopathological factors was analyzed using the $\chi^{2}$ test. Survival curves were plotted using the Kaplan-Meier method, and the log-rank test was employed for analysis. Multivariate analysis was performed using Cox's proportional hazards model. The risk rate and its $95 \%$ confidence interval were recorded for each marker. $\mathrm{P}<0.05$ was considered to indicate a statistically significant difference.

\section{Results}

The expression of Emil in human ESCC tissue samples. To reveal the role of Emi1 in ESCC, the expression of Emi1 protein was detected by western blot analysis in 8 paired frozen ESCC tumor tissues and para-cancerous tissues. The results revealed that Emil expression was significantly increased in 6 of 8 tumors, compared with para-cancerous tissues $(\mathrm{P}<0.05$; Fig. 1). In addition, expression of Emil and Ki-67 was simultaneously detected and further verified in 90 ESCC samples by immunohistochemical staining. The results indicated that Emil and Ki-67 proteins were overexpressed in ESCC 
Table I. Association between Emi1 protein expression and clinicopathological features of esophageal squamous cell carcinoma specimens.

\begin{tabular}{|c|c|c|c|c|}
\hline \multirow[b]{2}{*}{ Variables } & \multirow[b]{2}{*}{ Cases (n) } & \multicolumn{2}{|c|}{ Emi1 expression } & \multirow[b]{2}{*}{ P-value } \\
\hline & & $\begin{array}{c}\text { Negative } \\
\text { (final score, } 0-2 ; n=32 \text { ) }\end{array}$ & $\begin{array}{l}\text { Positive } \\
\text { (final score } 3-7 ; n=58 \text { ) }\end{array}$ & \\
\hline Age, years & & & & 0.244 \\
\hline$\leq 60$ & 46 & 19 & 27 & \\
\hline$>60$ & 44 & 13 & 31 & \\
\hline Gender & & & & 0.120 \\
\hline Male & 55 & 23 & 32 & \\
\hline Female & 35 & 9 & 26 & \\
\hline Histological differentiation & & & & $0.032^{\mathrm{a}}$ \\
\hline Well & 20 & 12 & 8 & \\
\hline Moderately & 50 & 15 & 35 & \\
\hline Poorly & 20 & 5 & 15 & \\
\hline Lymphatic metastasis & & & & $0.006^{\mathrm{a}}$ \\
\hline Positive & 23 & 9 & 34 & \\
\hline Negative & 67 & 23 & 24 & \\
\hline Tumor diameter, cm & & & & 0.755 \\
\hline$\leq 5$ & 80 & 28 & 52 & \\
\hline$>5$ & 10 & 4 & 6 & \\
\hline Tumor depth & & & & 0.079 \\
\hline $\mathrm{T} 1$ & 7 & 3 & 4 & \\
\hline $\mathrm{T} 2$ & 6 & 5 & 1 & \\
\hline $\mathrm{T} 3$ & 22 & 7 & 15 & \\
\hline $\mathrm{T} 4$ & 55 & 17 & 38 & \\
\hline Ki-67 expression, \% & & & & $0.028^{\mathrm{a}}$ \\
\hline$\leq 0.78$ & 45 & 21 & 24 & \\
\hline$>0.78$ & 45 & 11 & 34 & \\
\hline
\end{tabular}

${ }^{\text {aS }}$ Statistical analyses were performed with the Pearson's $\chi^{2}$ test. $\mathrm{P}<0.05$ was considered to indicate a statistically significant difference. Emil, early mitotic inhibitor- 1 .

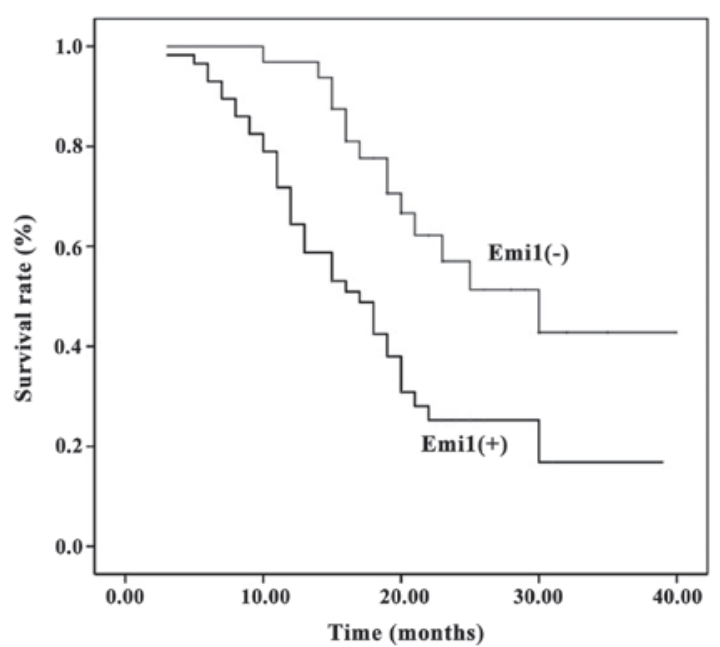

Figure 3. Prognostic significance of Emil expression in human ESCC samples. Kaplan-Meier survival curves revealed that, compared with low expression of Emi1, its overexpression was correlated with poor survival in ESCC patients ( $\mathrm{P}=0.001$, log-rank test). Emi1, early mitotic inhibitor-1; ESCC, esophageal squamous cell carcinoma. specimens, whereas in the matching para-cancerous tissue samples, their expression was weak or absent (Fig. 2).

Correlation of Emil protein expression with clinicopathological variables in human ESCC tissues. The association between Emil expression and clinicopathological variables was evaluated. For statistical analysis of Emil expression, the ESCC tissue specimens were classified into positive or negative groups, based on their final staining scores. As presented in Table I, Emil expression was correlated with histological differentiation $(\mathrm{P}=0.032)$ and lymphatic metastasis $(\mathrm{P}=0.006)$, while no correlation existed between Emi1 expression and other prognostics factors, including age, gender, tumor diameter and tumor depth. Furthermore, a positive correlation existed between Emil and Ki-67 expression (which is indicative of proliferative activity) in the majority of specimens $(\mathrm{P}=0.028)$.

Prognostic significance of Emil expression in human ESCC samples. Survival information was available for all patients 
Table II. Contribution of various potential prognostic factors to survival in patients with esophageal squamous cell carcinoma.

\begin{tabular}{lccc}
\hline Variables & Hazard ratio & 95\% Confidence interval & P-value \\
\hline Age & 1.143 & $0.655-1.995$ & 0.638 \\
Gender & 0.898 & $0.483-1.668$ & 0.733 \\
Histological differentiation & 0.641 & $0.416-1.624$ & 0.571 \\
Tumor diameter & 1.485 & $0.652-3.383$ & 0.346 \\
Tumor depth & 1.171 & $0.800-1.713$ & 0.416 \\
Lymphatic metastasis & 0.822 & $0.421-0.976$ & $0.018^{\mathrm{a}}$ \\
Emil expression & 1.967 & $1.024-3.782$ & $0.042^{\mathrm{a}}$ \\
Ki-67 expression & 3.047 & $1.554-5.973$ & $0.001^{\mathrm{a}}$ \\
\end{tabular}

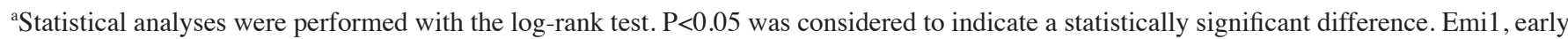
mitotic inhibitor-1.

A

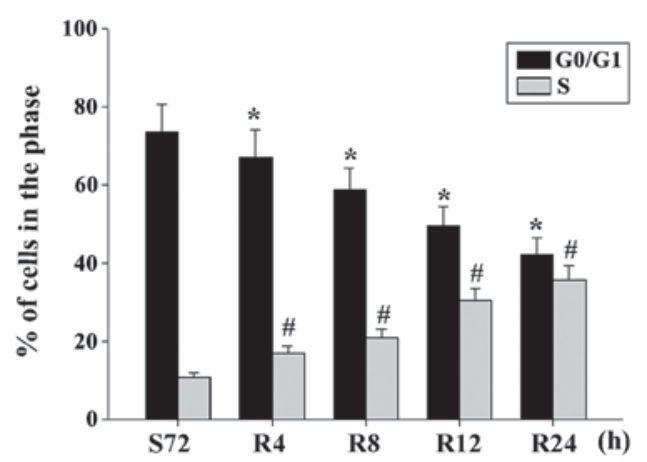

B

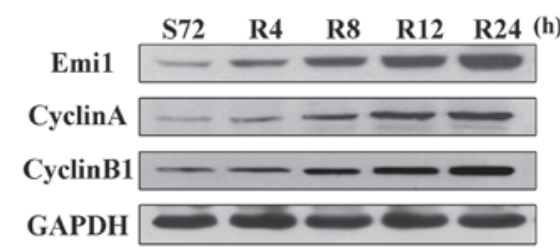

C

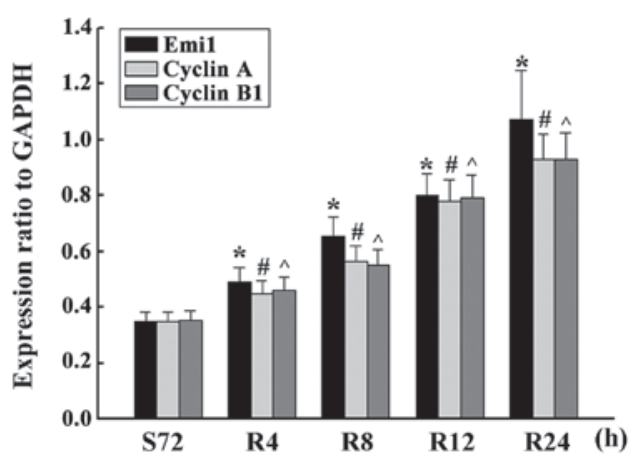

Figure 4. Overexpression of Emi1 and cell cycle-related molecules in proliferating esophageal squamous cell carcinoma cells. (A) ECA109 cells were synchronized at G1, and induced to progress into the cell cycle by serum addition at $0,4,8,12$ and $24 \mathrm{~h}$. Upon cell cycle progression induction, the majority of cells were in the $\mathrm{S}$ phase. Data represent the mean \pm standard deviation of three independent experiments ${ }^{*}, \mathrm{P}<0.01$ vs. control (S72 h). (B) ECA109 cells were serum starved for $72 \mathrm{~h}$, and following serum addition, cell lysates were prepared and analyzed by western blotting using antibodies against Emi1, cyclin A and cyclin B1. GAPDH was used as a control for protein loading and integrity. (C) Ratio of Emil, cyclin A and cyclin B1 protein levels to those of GAPDH for each time point, as analyzed by densitometry. Data represent the mean \pm standard error of the mean $(n=3)$. ${ }^{* \#, \wedge} \mathrm{P}<0.01$, vs. control $(\mathrm{S} 72 \mathrm{~h})$. $\mathrm{S}$, serum starvation; R, serum addition; Emi1, early mitotic inhibitor-1; GAPDH, glyceraldehyde 3-phosphate dehydrogenase.
A

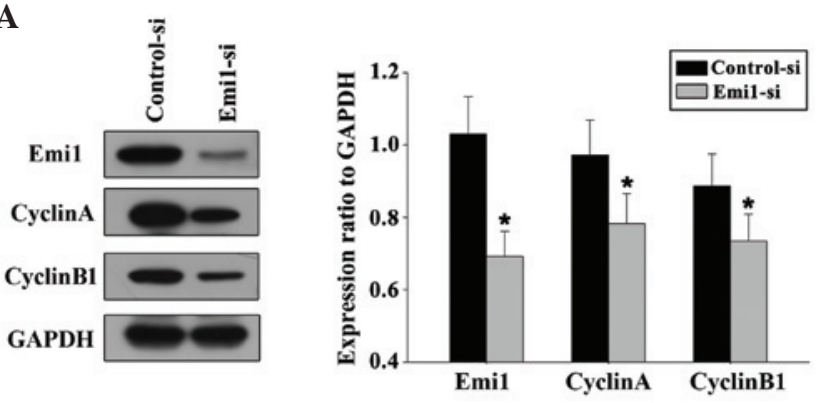

$\mathbf{B}$

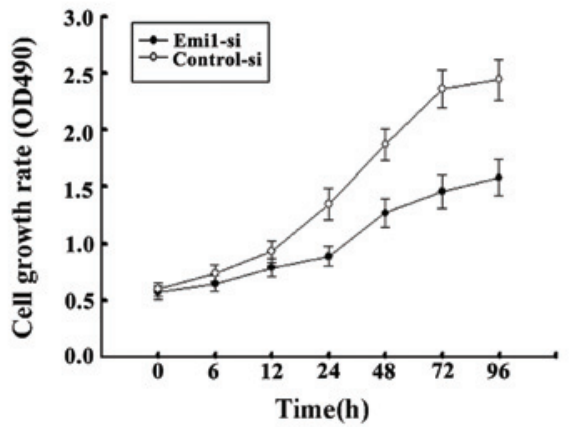

C
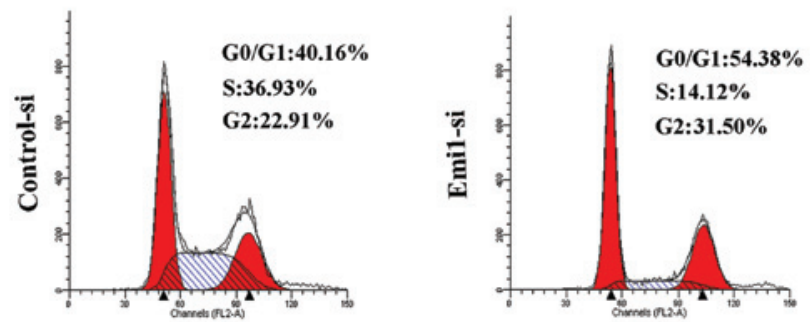

Figure 5. Silencing Emil expression suppressed the proliferation of esophageal squamous cell carcinoma cells and the expression of cell cycle-related molecules in these cells. (A) ECA109 cells were transiently transfected with siRNA targeting Emi1 (Emi1-sil and Emi1-si2) or with a scrambled control siRNA sequence (control-si) for $48 \mathrm{~h}$, and immunoblot analysis of Emi1, cyclin A, cyclin B1 and glyceraldehyde 3-phosphate dehydrogenase was then performed, ${ }^{*} \mathrm{P}<0.05$ vs. control. (B) The growth curve of ECA109 cells treated with Emi1-si1 was compared with that of control-si-treated cells by Cell Counting Kit-8 assay at the indicated time points. Silencing Emil resulted in a significant inhibition in cell growth rate $(\mathrm{P}=0.001)$. (C) At $48 \mathrm{~h}$ post-transfection, cells were stained with propidium iodide for analysis of their DNA content by fluorescence-activated cell sorting. Flow cytometry demonstrated that Emil inhibited the cell cycle at the G1/S transition. Emi1, early mitotic inhibitor-1; GAPDH, glyceraldehyde 3-phosphate dehydrogenase; si, small interfering; OD, optical density. 
at the end of clinical follow-up. Kaplan-Meier survival curves for univariate analysis demonstrated that Emi1 protein overexpression resulted in a poor survival rate $(\mathrm{P}<0.05)$ (Fig. 3). According to the Cox's proportional hazards regression model, Emi1 expression, Ki67 expression and lymphatic metastasis were independent prognostic factors of poor prognosis in ESCC patients (Table II).

Emil is involved in ESCC cell proliferation. To demonstrate whether Emil expression was cell cycle-dependent in ESCC cells, the cell cycle was analyzed following serum starvation and upon re-feeding with serum. ECA109 cells were arrested in the G1 phase by serum deprivation for $72 \mathrm{~h}$, and the percentage of cells in the G1 phase increased from 39.08 to $73.35 \%$ under these conditions (Fig. 4A). Upon serum addition, the cells were released from the G1 phase and reentered the $\mathrm{S}$ phase. As expected, the expression of Emi1 increased as early as $4 \mathrm{~h}$ post-serum stimulation in ECA109 cells. Additionally, the expression of cyclins $\mathrm{A}$ and $\mathrm{B}$ was upregulated (Fig. 4B and C). These results indicate that Emil is important role in the regulation of cell proliferation.

siRNA targeting Emil inhibits ESCC cell proliferation. By transfecting ECA109 cells with Emil-siRNA or control siRNA, the influence of Emil on ESCC cell proliferation was further evaluated. In the present study, two siRNAs targeting Emil (Emi1-si1 and Emi1-si2) were tested, and the efficiency of Emil gene silencing was measured by immunoblotting. The results demonstrated that Emil-sil exerted a better silencing effect. Decreased expression of cyclins A and B was detected in Emi-sil (Fig. 5A). This result was in agreement with a previous study that reported that Emil promoted mitotic entry to enable accumulation of cyclins A and B1 (15). Flow cytometry confirmed that Emil-si could inhibit the cell cycle at the G1-S transition (Fig. 5B). Silencing of Emi1 led to a significant inhibition of the rate of cell growth (Fig. 5C). These findings further suggested that Emil may be involved in the regulation of the G1-S transition, which could be responsible for the increased growth rate of ESCC cells.

\section{Discussion}

Thanks to the advances in molecular and cellular biology of tumors, it is well known that the occurrence of EC is partly due to acquired alterations in oncogenes and tumor suppressor genes (4). Cell proliferation, differentiation and cell cycle control disorders are important features in cancer (1). Misregulation of the G1-S transition is an essential component of the cellular transformation process in the cell cycle, and G1-S regulatory defects have been reported in numerous types of human malignancies (22-24).

Emil was firstly identified in a yeast two-hybrid screen for F-box proteins using S-Phase kinase-associated protein 1 as bait (17). In mammalian cells, Emi1 levels are regulated during the cell cycle, with its transcription being induced at the G1-S transition under the control of E2F, which is required to stabilize cyclins A and B, and enables cells to initiate the $\mathrm{S}$ phase (18). A previous study indicated that Emil is accumulated in ovarian clear cell carcinoma (25), and Liu et al (26) reported that Emil overexpression may be a poor prognostic marker for breast carcinoma patients. These findings suggested that the Emil gene may be involved in human cell cycle disorders and may lead to oncogenesis.

To the best of our knowledge, Emil expression in ESCC specimens has not been actively studied thus far. The present study is the first to report that Emil protein is overexpressed in human ESCC, and analyze a possible association between Emil expression and clinicopathological factors and prognosis of patients with ESCC. In the present study, immunoblotting examined the protein expression levels of Emil in ESCC specimens and para-cancerous tissues. Furthermore, the expression of Emil was investigated to confirm the participation of Emil in tumor progression by immunohistochemical staining. High expression of Emil as a useful marker of tumor proliferative activity $(27,28)$ was correlated with overexpression of Ki-67. Therefore, increased Emil levels may be closely associated with the pathogenesis of ESCC. In addition, the association between Emil expression and clinicopathological variables and patient prognosis was evaluated. The results revealed that Emil expression was strongly correlated with histological differentiation and lymphatic metastasis. The results of survival analysis demonstrated that high expression of Emil was strongly correlated with poor prognosis, while multivariate analysis revealed that high expression of Emi1 was an independent unfavorable prognostic factor. These findings indicated that Emil may be a reliable factor of prognosis in patients with EC.

The expression of Emi1 during cell cycle progression was further detected in ESCC cells in vitro. The results indicated that the expression of Emi1 was upregulated during the G1-S phase transition. These results confirmed the association of Emi1 expression with ESCC development. Furthermore, the present data revealed that silencing Emi1 expression could suppress ECA109 cell proliferation. This observation is consistent with a previous study in which Emil promoted mitotic entry and enabled accumulation of cyclins A and B1 (15).

Hsu et al (18) demonstrated that upregulation of Emi1 at the transcriptional level occurred in various tumors. At the G1-S transition, Emil was transcriptionally induced by the transcription factor E2F, which is associated with cell cycle control (18). The E2F signaling pathway is frequently activated in highly proliferative cells, and the central proteins of the retinoblastoma $(\mathrm{Rb}) / \mathrm{E} 2 \mathrm{~F}$ signaling pathway, including $\mathrm{p} 16^{\mathrm{INK} 4 \mathrm{a}}, \mathrm{Rb}$ and cyclin $\mathrm{D}$, are frequently mutated in cancer (29). This E2F activation is expected to cause an increase in Emil levels.

In summary, the present study demonstrated that Emi1 protein expression was increased in ESCC, and positively correlated with ESCC cell proliferation, indicating that Emil may play a key role in ESCC and it is an independent candidate prognostic factor for ESCC patients. However, further studies are required to clarify the molecular mechanisms of Emil in the pathogenesis of ESCC.

\section{References}

1. Ferlay J, Soerjomataram I, Dikshit R, Eser S, Mathers C, Rebelo M, Parkin DM, Forman D and Bray F: Cancer incidence and mortality worldwide: Sources, methods and major patterns in GLOBOCAN 2012. Int J Cancer 136: E359-E386, 2015. 
2. Pourhoseingholi MA, Vahedi M and Baghestani AR: Burden of gastrointestinal cancer in Asia; an overview. Gastroenterol Hepatol Bed Bench 8: 19-27, 2015.

3. Zeng H, Zheng R, Guo Y, Zhang S, Zou X, Wang N, Zhang L, Tang J, Chen J, Wei K, et al: Cancer survival in China, 2003-2005: A population-based study. Int J Cancer 136: 1921-1930, 2015.

4. Lagergren J and Lagergren P: Recent developments in esophageal adenocarcinoma. CA Cancer J Clin 63: 232-248, 2013.

5. Johnson DG and Walker CL: Cyclins and cell cycle checkpoints. Annu Rev Pharmacol Toxicol 39: 295-312, 1999.

6. Wolgemuth DJ and Roberts SS: Regulating mitosis and meiosis in the male germ line: Critical functions for cyclins. Philos Trans R Soc Lond B Biol Sci 365: 1653-1662, 2010.

7. Kronja I and Orr-Weaver TL: Translational regulation of the cell cycle: When, where, how and why? Philos Trans R Soc Lond B Biol Sci 366: 3638-3652, 2011.

8. Wang Y, Fei M, Cheng C, Zhang D, Lu J, He S, Zhao Y, Wang Y and Shen A: Jun activation domain-binding protein 1 negatively regulate p27 kip1 in non-Hodgkin's lymphomas. Cancer Biol Ther 7: 460-467, 2008.

9. Song Y, Zhao C, Dong L, Fu M, Xue L, Huang Z, Tong T, Zhou Z, Chen A, Yang Z, et al: Overexpression of cyclin B1 in human esophageal squamous cell carcinoma cells induces tumor cell invasive growth and metastasis. Carcinogenesis 29: 307-315, 2008.

10. Takeno S, Noguchi T, Kikuchi R, Uchida Y, Yokoyama S and Müller W: Prognostic value of cyclin B1 in patients with esophageal squamous cell carcinoma. Cancer 94: 2874-2881, 2002.

11. Nozoe T, Korenaga D, Kabashima A, Ohga T, Saeki H and Sugimachi K: Significance of cyclin B1 expression as an independent prognostic indicator of patients with squamous cel carcinoma of the esophagus. Clin Cancer Res 8: 817-822, 2002.

12. Chetty R and Simelane S: p53 and cyclin A protein expression in squamous carcinoma of the oesophagus. Pathol Oncol Res 5 : 193-196, 1999.

13. Bernis C, Vigneron S, Burgess A, Labbé JC, Fesquet D, Castro A and Lorca T: Pin1 stabilizes Emi1 during G2 phase by preventing its association with SCF(betatrcp). EMBO Rep 8: 91-98, 2007.

14. Miller JJ, Summers MK, Hansen DV, Nachury MV, Lehman NL, Loktev A and Jackson PK: Emil stably binds and inhibits the anaphase-promoting complex/cyclosome as a pseudosubstrate inhibitor. Genes Dev 20: 2410-2420, 2006.

15. Moshe Y, Bar-On O, Ganoth D and Hershko A: Regulation of the action of early mitotic inhibitor 1 on the anaphase-promoting complex/cyclosome by cyclin-dependent kinases. J Biol Chem 286: 16647-16657, 2011.

16. Reimann JD, Gardner BE, Margottin-Goguet F and Jackson PK Emil regulates the anaphase-promoting complex by a different mechanism than Mad2 proteins. Genes Dev 15: 3278-3285, 2001
17. Reimann JD, Freed E, Hsu JY, Kramer ER, Peters JM and Jackson PK: Emil is a mitotic regulator that interacts with Cdc20 and inhibits the anaphase promoting complex. Cell 105: 645-655, 2001.

18. Hsu JY, Reimann JD, Sørensen CS, Lukas J and Jackson PK E2F-dependent accumulation of hEmil regulates S phase entry by inhibiting APC (Cdh1). Nat Cell Biol 4: 358-366, 2002.

19. Margottin-Goguet F, Hsu JY, Loktev A, Hsieh HM, Reimann JD and Jackson PK: Prophase destruction of Emil by the SCF (betaTrCP/Slimb) ubiquitin ligase activates the anaphase promoting complex to allow progression beyond prometaphase. Dev Cell 4: 813-826, 2003.

20. Zhao Y, Tang Q, Ni R, Huang X, Wang Y, Lu C, Shen A, Wang Y, Li C, Yuan Q, et al: Early mitotic inhibitor-1, an anaphase-promoting complex/cyclosome inhibitor, can control tumor cell proliferation in hepatocellular carcinoma: Correlation with Skp2 stability and degradation of p27(Kip1). Hum Pathol 44: 365-373, 2013.

21. Masunaga R, Kohno H, Dhar DK, Ohno S, Shibakita M, Kinugasa S, Yoshimura $\mathrm{H}$, Tachibana M, Kubota $\mathrm{H}$ and Nagasue N: Cyclooxygenase-2 expression correlates with tumor neovascularization and prognosis in human colorectal carcinoma patients. Clin Cancer Res 6: 4064-4068, 2000.

22. Roth JA and Cristiano RJ: Gene therapy for cancer: What have we done and where are we going? J Natl Cancer Inst 89: 21-39, 1997.

23. Sherr CJ: Cancer cell cycles. Science 274: 1672-1677, 1996.

24. Roncalli M, Bosari S, Marchetti A, Buttitta F, Bossi P, Graziani D, Peracchia A, Bonavina L, Viale G and Coggi G: Cell cycle-related gene abnormalities and product expression in esophageal carcinoma. Lab Invest 78: 1049-1057, 1998.

25. Gütgemann I, Lehman NL, Jackson PK and Longacre TA: Emi1 protein accumulation implicates misregulation of the anaphase promoting complex/cyclosome pathway in ovarian clear cell carcinoma. Mod Pathol 21: 445-454, 2008.

26. Liu X, Wang H, Ma J, Xu J, Sheng C, Yang S, Sun L and Ni Q: The expression and prognosis of Emil and Skp2 in breast carcinoma: Associated with PI3K/Akt pathway and cell proliferation. Med Oncol 30: 735, 2013.

27. Sheri A and Dowsett M: Developments in Ki67 and other biomarkers for treatment decision making in breast cancer. Ann Oncol 23 (Suppl 10): x219-x227, 2012.

28. He WL, Li YH, Yang DJ, Song W, Chen XL, Liu FK, Wang Z, Li W, Chen W, Chen CY, et al: Combined evaluation of centromere protein $\mathrm{H}$ and $\mathrm{Ki}-67$ as prognostic biomarker for patients with gastric carcinoma. Eur J Surg Oncol 39: 141-149, 2013.

29. Harbour JW and Dean DC: The Rb/E2F pathway: Expanding roles and emerging paradigms. Genes Dev 14: 2393-2409, 2000 . 